\title{
In vitro Studies in Litchi chinensis - Effect of Explant and Medium
}

\author{
Kumari Anjani* and Harsh Kumar \\ Department of Agricultural Biotechnology and Molecular Biology, Dr. Rajendra Prasad \\ Central Agricultural University, Pusa-848125, Bihar, India \\ *Corresponding author
}

\begin{abstract}
A B S T R A C T
Keywords

Litchi, Kinetin, Callogenesis

Article Info

Accepted:

20 March 2018

Available Online:

10 April 2018

Litchi is a very important fruit of the Indian subcontinent and has a great demand in local and international market. But it is a very troublesome plant to cultivate and the current production rate cannot meet the growing demands of litchi. The in vitro techniques can be used to rapidly increase production. The present study was carried out to develop a rapid micropropagation protocol for litchi by studying the effect of medium and the explant used. The apical bud was found to be the most suitable explant among the four explants used. Out of the nine medium used for the study, MS 1, MS 2 MS 7 and MS 9 were the most effective medium for callogenesis in apical bud. The frequency of callogenesis was more on medium containing 2,4-D in higher concentration and low kinetin and also in medium with higher concentration of kinetin and low 2,4-D.
\end{abstract}

\section{Introduction}

Litchi, a native of China and Thailand, has been an important fruit in Southeastern Asia for over 2000 years. It is the second most important fruit crop after mango that is cultivated in most parts of the world (Das et al., 2016). In India, it is cultivated in some part of Bihar, Himachal Pradesh, Uttar Pradesh and West Bengal. The litchi plant is a tree, belonging to the family Sapindaceae, which reaches a height of 35 to 40 feet and has a broad round topped crown and leathery shiny leaves. The fruits are very distinctive and their edible part is aril that covers the seed. Litchi fruit has deliciously flavored, sweet, juicy and pearly white flesh which is a rich source of vitamin $\mathrm{C}$. The litchi fruit has strong antioxidant, anti-cancerous, anti- diabetic, antimicrobial, anti-inflammatory activities along with free radical scavenging and hepatic protection properties (Naskar and Mazumder, 2015; Taak and Koul, 2016; Emanuele et al., 2017). It is regarded as a functional fruit (Emanuele et al., 2017). Litchi is also utilized as an excellent canned fruit. A highly flavored squash is prepared from inferior fruits which are liked by many during summer months.

The tree is also valuable for ornamental purposes apart from its fruits, various other products, such as pickles, jam, jelly, wine, candy, litchi nut etc. are also made from litchi (Goto, 1960). The peel extract of litchi is found to be a useful ingredient in anti-aging and skin lightening cosmetic products (Lourith et al., 2017). The high demand and the high 
prices paid for litchi has created new interest in the growing of this fruit with an increase in the demand for propagation materials.

Besides its economic importance, plantation of new litchi cultivars is very troublesome through conventional methods due to its long reproductive cycle and highly heterozygous genetic background. Litchi is basically a plant of tropics and is grown in areas where there is cool dry, frost free winter and long hot summer with high rainfall and humidity (Taak and Koul, 2016). Only 6 to 9 month old healthy plants with fine roots can be used for plantation. The plants are planted by making a small hole in the centre of the pit sufficient to the soil ball. The new plants are inoculated with mycorrhizal planting for good results of growth. The land should not be allowed to dry completely. Planting should be immediately followed by irrigation. In case of high wind plants are tied to the stake.

The most valued plants of litchi are those which produce 'chicken tongue', i.e. fruits with aborted seeds. But most of these plants are lost prior to harvest and cannot be propagated by seeds. For these reasons, in vitro propagation techniques can be used for the efficient propagation of the litchi plants.

Litchi is a problematic plant for tissue culture (Kantharajah et al., 1989; Das et al., 2016) but its tissue culture has many advantages like high and regular yield and which is free from showing biennial tendency; large fruit size and a large number of fruits per panicle; small seed size or higher aril percentage of aborted seeded plants; good fruit quality; resistance to physiological disorders and insect pests like fruit borers; wide adaptability to diverse ecological condition and desirable tree characteristics. Thus, this study was carried to standardize the protocol for micropropagation of litchi and develop a method of clonal propagation of this important plant.

\section{Materials and Methods}

Murashige and Skoog (1962) (MS) medium was used as basal medium during the study which was supplemented with different concentration and combination of phytohormones.

Nine different medium were used for the tissue culture of litchi. The composition of the medium used for the study is listed in Table 1.

\section{Pre-sterilization of explants}

The explants used for the study were leaves, nodes, internodes and apical bud. The explants were first cut (size about 1-2 cm) with the help of sharp knife.

These were first washed gently with $1 \%$ setavelon solution for 2-3 minute and then washed with running tap water to remove the detergent.

\section{Pre-treatment of explants}

One of the problems in the micropropagation of litchi is the secretion of polyphenols into the medium by the tissues. The polyphenols undergo oxidation to produce substances that kill the tissues (Kantharajah et al., 1992). Another problem is that field grown litchi plant, used as a source explant, is heavily contaminated with organisms which are difficult to remove prior to culture.

Thus, before inoculation the explants are treated with pretreatment solution. The pretreatment solution contains free oxygen which makes the phenol inactive. The composition of pretreatment solution is as given in Table 2. After washing with tap water, the explants were transferred to sterilized beaker and then kept in pretreatment solution for about $15 \mathrm{~min}$. These explants were then washed with sterilized distilled water. 
Surface sterilization of explants and inoculation

The pre-sterilized explants were treated with $0.1 \%$ mercuric chloride solution for $10 \mathrm{~min}$ in the laminar air flow hood for surface sterilization. The explants were then washed with sterilized distilled water three times to remove the excess mercuric chloride. The pretreated and surface sterilized explants were inoculated in media containing culture tubes over the flame of sprit lamp. The inoculation was carried out in the laminar air flow.

The culture tubes were transferred to a thermal insulated temperature controlled tissue culture room with temperature around $25^{\circ} \mathrm{C}$ and relative humidity $60-80 \%$. The continuous light of about 2000-4000 lux was provided through fluorescent tubes. Three types of response namely establishment, swelling and callogenesis were observed in the cultured tubes.

\section{Results and Discussion}

The four explants namely leaf, node, internode and apical bud of shoot were inoculated on nine different MS media with varying concentrations of phytohormones (2, 4-D and kinetin). The explants showed swelling after 6-7 days of inoculation while callus formation was visible only after 10-12 days. Some tubes also exhibited browning of the explants and media. The contamination mainly fungal was also present in some of the cultured tubes which can be attributed to mycorrhizal associations. The callus formation was seen mostly in the areas which were in direct contact of the media. The callus obtained in all the cultures was friabal callus which were either creamish or greenish in colour.

\section{Effect of medium on response of leaf}

Most of the medium showed a $100 \%$ establishment in leaf. For frequency of swelling of explant, the most responsive medium were MS 1 and MS 8, while no swelling was observed on MS 4 and MS 5. For callogenesis, only MS 2, MS 3, MS 8 and MS 9 were effective. MS 8 was found to be the most suitable medium for all responses in leaf (Table 3 and Fig. 1).

\section{Effect of medium on response of node}

The node showed establishment on all medium with the highest on MS 1, MS 2, MS 4 , MS 8 and MS 9. The swelling of the explant was observed on all medium except MS 2, MS 4, MS 8 and MS9 with the highest on MS 1. All media were not very responsive for callogenesis and it was only observed on the media MS 1, MS 3, MS 5 and MS 6 (Table 4 and Fig. 2).

\section{Effect of medium on response of internode}

The internode was not a very responsive explant and did not show very significant response on any medium. However, establishment of internode was observed on medium MS 3, MS 4, MS 5, MS 7, MS 8 and MS 9 (Table 5 and Fig. 3).

\section{Effect of medium on response of apical bud}

The apical bud was very responsive on all medium and showed a $100 \%$ establishment on all medium except MS 5. The swelling of the explant was observed on all media except MS 5 , MS 6 and MS 8. The highest frequency of swelling was observed on MS 2 and MS 3. The callogenesis was observed on MS 1, MS 2 MS 7 and MS 9. For all responses, MS 2 was the best medium for the explant apical bud (Table 6 and Fig. 4).

\section{Cumulative effect of medium and explant}

The highest establishment frequency was observed in apical bud (97.78\%) and lowest in internode $(62.22 \%)$. 
Table.1 Various medium used for the investigation

\begin{tabular}{|c|c|c|}
\hline MEDIUM & $\begin{array}{c}\text { CONCENTRA TION OF } \\
\text { NO. }\end{array}$ & CONCENTRA TION OF 2,4-D (mg/L) \\
\hline MS 1 & 0 & 0 \\
\hline MS 2 & 2.0 & 0 \\
\hline MS 3 & 4.0 & 2.0 \\
\hline MS 4 & 0 & 2.0 \\
\hline MS 5 & 2.0 & 2.0 \\
\hline MS 6 & 4.0 & 2.0 \\
\hline MS 7 & 0 & 4 \\
\hline MS 8 & 2.0 & 4.0 \\
\hline MS 9 & 4.0 & 4.0 \\
\hline
\end{tabular}

Table.2 Pretreatment solution of litchi

\begin{tabular}{|l|l|}
\hline Ascorbic acid & $5 \mathrm{gm}$ \\
\hline Citric acid & $5 \mathrm{gm}$ \\
\hline Bavistin & $1 \mathrm{gm}$ \\
\hline Streptomycin & $1 \mathrm{gm}$ \\
\hline Distilled water & $500 \mathrm{ml}$ \\
\hline
\end{tabular}

Table.3 Effect of medium on response of leaf

\begin{tabular}{|c|c|c|c|}
\hline Medium & $\begin{array}{c}\text { ESTABLISHMENT } \\
\text { FREQUENCY }(\boldsymbol{\%})\end{array}$ & $\begin{array}{c}\text { FREQUENCY OF SWELLING OF } \\
\text { EXPLANT }(\boldsymbol{\%})\end{array}$ & $\begin{array}{c}\text { FREQUENCY OF } \\
\text { CALLOGENESIS (\%) }\end{array}$ \\
\hline MS 1 & 100 & 100 & - \\
\hline MS 2 & 100 & 80 & 60 \\
\hline MS3 & 100 & 33 & - \\
\hline MS 4 & 100 & - & - \\
\hline MS 5 & 100 & - & - \\
\hline MS 6 & 75 & 25 & 100 \\
\hline MS 7 & 100 & 50 & 75 \\
\hline MS 8 & 100 & 100 & - \\
\hline
\end{tabular}

Table.4 Effect of medium on response of node

\begin{tabular}{|c|c|c|c|}
\hline MEDIUM & $\begin{array}{c}\text { ESTABLISHMENT } \\
\text { FREQUENCY (\%) }\end{array}$ & $\begin{array}{c}\text { FREQUENCY OF SWELLING OF } \\
\text { EXPLANT (\%) }\end{array}$ & $\begin{array}{c}\text { FREQUENCY OF } \\
\text { CALLOGENESIS (\%) }\end{array}$ \\
\hline MS 1 & 100 & 100 & 66 \\
\hline MS 2 & 100 & - & - \\
\hline MS3 & 75 & 50 & - \\
\hline MS 4 & 100 & - & 25 \\
\hline MS 5 & 75 & 50 & - \\
\hline MS 6 & 83 & 50 & - \\
\hline MS 7 & 50 & 50 & - \\
\hline MS 8 & 100 & - & - \\
\hline
\end{tabular}


Table.5 Effect of medium on response of internode

\begin{tabular}{|c|c|c|c|}
\hline MEDIUM & $\begin{array}{c}\text { ESTABLISHMENT } \\
\text { FREQUENCY (\%) }\end{array}$ & $\begin{array}{c}\text { FREQUNCY } \\
\text { OF } \\
\text { SWELLING } \\
\text { OF EXPLANT } \\
(\%)\end{array}$ & $\begin{array}{c}\text { FREQUENCY } \\
\text { OF }\end{array}$ \\
\hline MS 1 & - & - & - \\
\hline MS 2 & - & - & - \\
\hline MS3 & 100 & - & - \\
\hline MS 4 & 100 & - & - \\
\hline MS 5 & 100 & - & - \\
\hline MS 6 & - & - & - \\
\hline MS 7 & 60 & - & - \\
\hline MS 8 & 100 & - & - \\
\hline MS 9 & 100 & - & - \\
\hline
\end{tabular}

Table.6 Effect of medium on response of apical bud

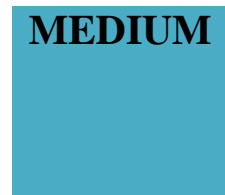

\begin{tabular}{c|c} 
ESTABLISHMEN & FREQUENCY \\
T FREQUENCY & OF SWELLING \\
$(\%)$ & OF EXPLANT \\
& $(\%)$
\end{tabular}

FREQUENCY OF CALLOGENESIS (\%)

\begin{tabular}{|l|}
\hline MS 1 \\
\hline MS 2 \\
\hline MS3 \\
\hline MS 4 \\
\hline MS 5 \\
\hline MS 6 \\
\hline MS 7 \\
\hline MS 8 \\
\hline MS 9 \\
\hline
\end{tabular}

\begin{tabular}{|c|c|c|}
\hline 100 & 50 & 50 \\
\hline 100 & 100 & 66 \\
\hline 100 & 100 & - \\
\hline 100 & 20 & - \\
\hline 80 & - & - \\
\hline 100 & - & - \\
\hline 100 & 75 & 50 \\
\hline 100 & - & - \\
\hline 100 & 50 & 50 \\
\hline
\end{tabular}

Table.7 Cumulative effect of medium and explant

\begin{tabular}{|l|c|c|c|}
\hline EXPLANT & $\begin{array}{c}\text { ESTABLISHMENT } \\
\text { FREQUENCY (\%) }\end{array}$ & $\begin{array}{c}\text { FREQUENCY OF } \\
\text { SWELLING OF } \\
\text { EXPLANT }(\%)\end{array}$ & $\begin{array}{c}\text { FREQUENCY OF } \\
\text { CALLOGENESIS }\end{array}$ \\
\hline LEAF & 97.22 & 51.44 & 18.67 \\
\hline NODE & 87 & 33.33 & 18.44 \\
\hline INTERNODE & 62.22 & 0 & 0 \\
\hline APICAL & 97.78 & 43.89 & 24 \\
BUD & & & \\
\hline
\end{tabular}


Fig.1 Effect of medium on response of leaf

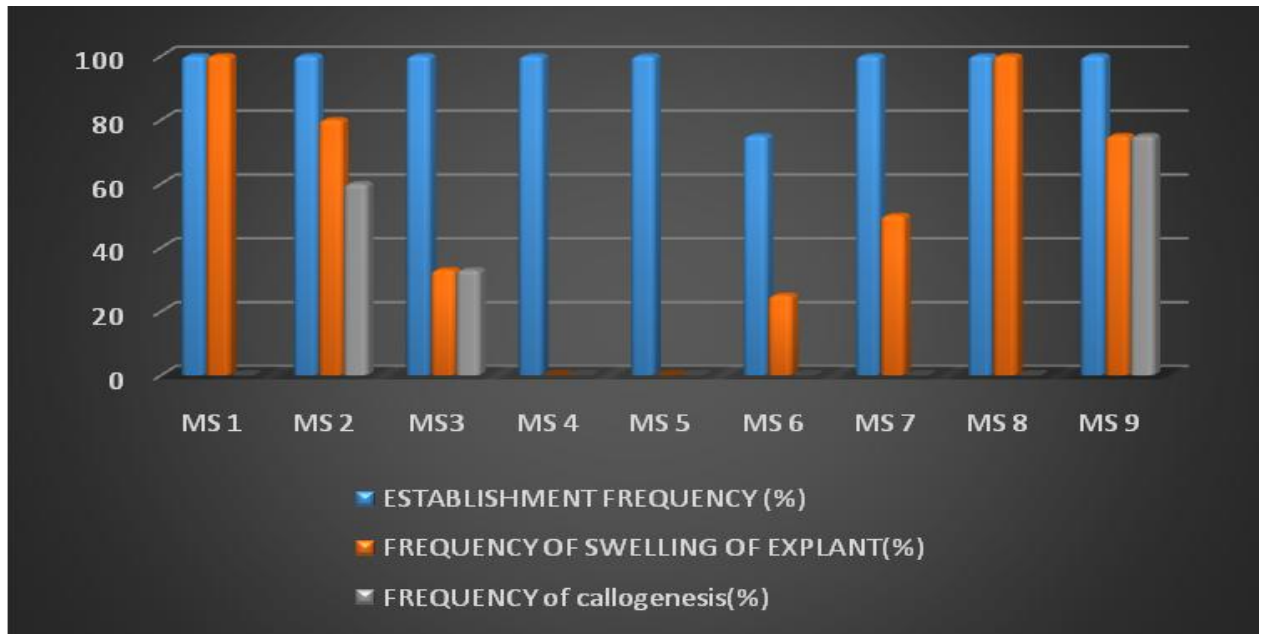

Fig.2 Effect of medium on response of node

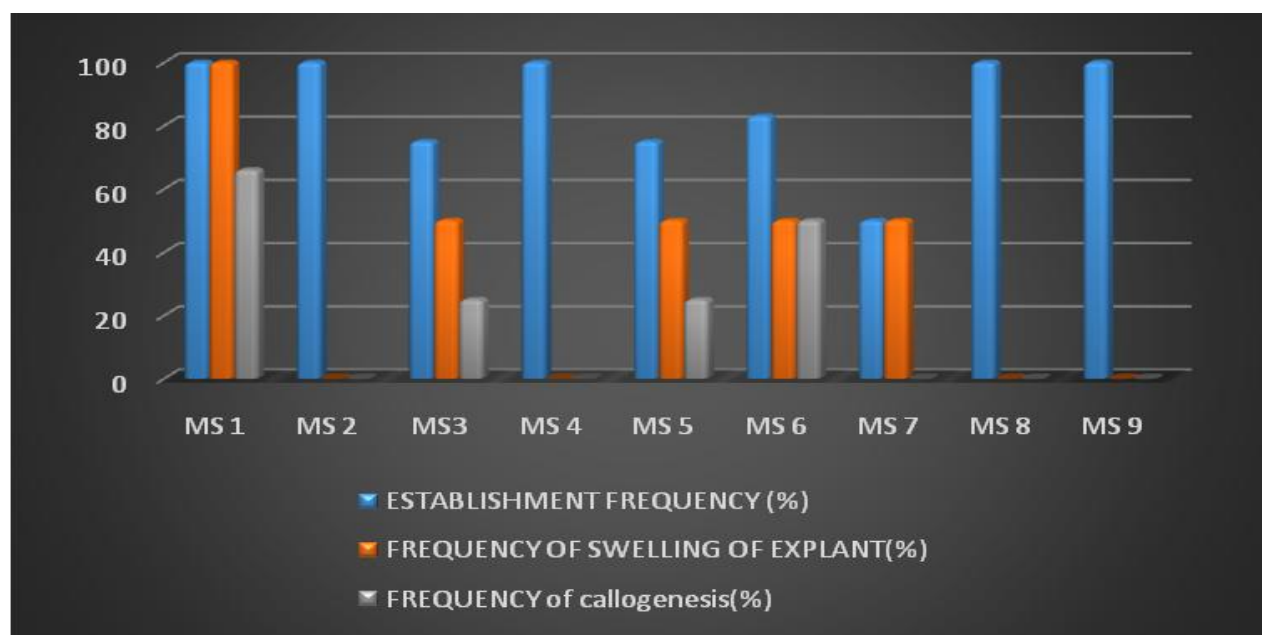

Fig.3 Effect of medium on response of internode

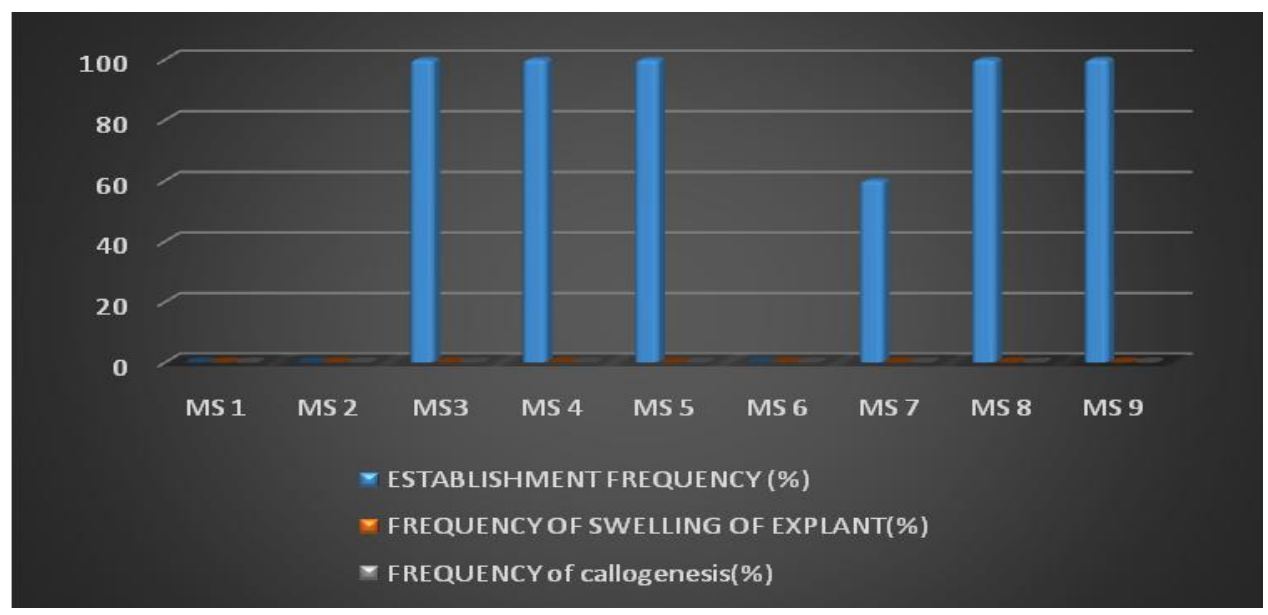


Fig.4 Effect of medium on response of apical bud

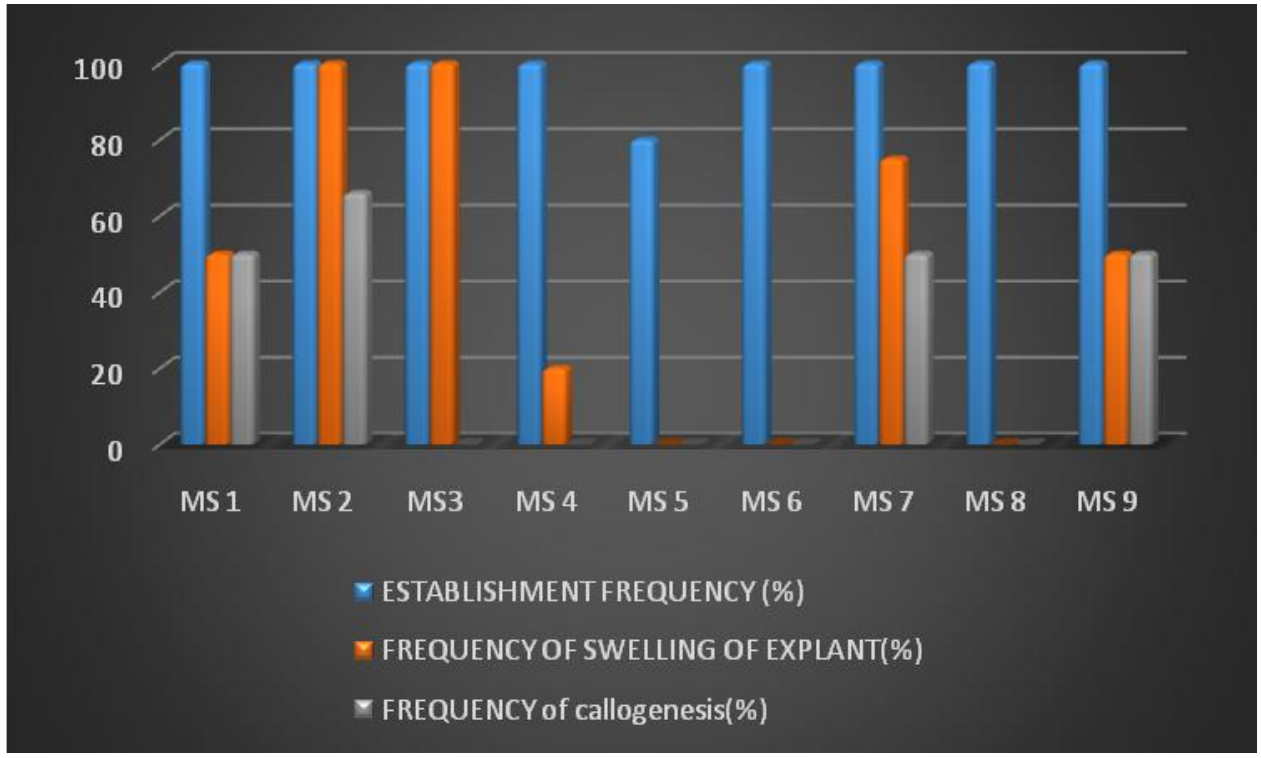

Fig.5 Cumulative effect of medium and explant

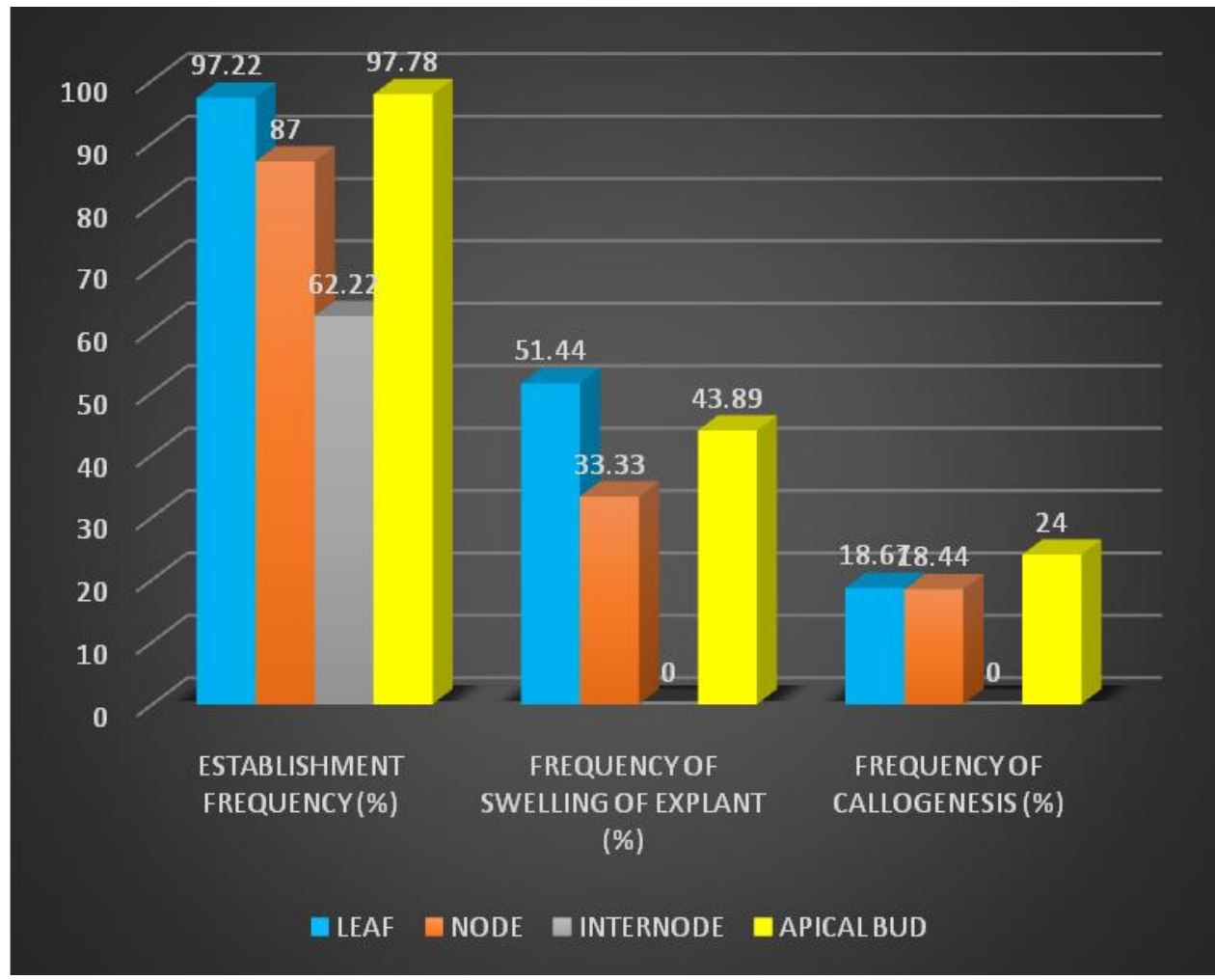

While the node as explant showed highest frequency of swelling of explant (51.44\%), internode did not showed this response. The frequency of callogenesis was the least observed response in all the explants with highest frequency being $24 \%$ in apical bud. The internode did not show this response also (Table 7 and Fig. 5). 
Litchi is believed to be a problematic plant for tissue culture and this was indicated by the results of the present study also. However, contradictory to previous findings certain significant results were observed in this study. Frequency of establishment of cultures did not show any regular pattern. However, the highest establishment frequency was observed in apical bud (97.78\%) and lowest in internode $(62.22 \%)$. This can be explained on the fact that establishment of culture is defined only on the basis of presence or absence of infection, the healthy state of explants i.e., whether it has died or exhibited browning. The component of the media has no effect on these aspects and thus do not affect frequency which was similar with the finding of earlier workers (Yu, 1991; Zhou et al., 1996; Das et al., 1999).

The node as explant showed highest frequency of swelling of explant $(51.44 \%)$ but the internode did not showed this response. For the leaf, the most responsive medium were MS 1 and MS 8, while no swelling was observed on MS 4 and MS 5. The swelling of the node explant was observed on all medium except MS 2, MS 4, MS 8 and MS9 with the highest on MS 1. The internode was not a very responsive explant and did not show very significant response on any medium. For apical bud, the swelling of the explant was observed on all media except MS 5, MS 6 and MS 8. The highest frequency of swelling was observed on MS 2 and MS 3. Swelling was more in medium containing higher concentration of kinetin and less concentration of 2,4-D than the medium containing more amount of 2,4-D and less concentration of kinetin. Because kinetin being a cytokinin promotes cell division, it causes more swelling than 2,4-D. Swelling was more in tubes with leaves and apical bud as explants perhaps because of the presence of meristematic tissue. Similar results were found by Das et.al. (1999) who showed multiple shoot induction from cotyledonary node following exposure to 88-8 $\mathrm{M}$ benzyl adenine in liquid Murashige and Skoog medium but Kantharajah et al., (1992) found that the shoot tip was the most responsive explant.

The frequency of callogenesis was the least observed response in all the explants with highest frequency being $24 \%$ in apical bud. The internode did not showed this response. For callogenesis in leaf, only MS 2, MS 3, MS 8 and MS 9 were found to be effective. All media were not very responsive for callogenesis in node and this response was only observed on the media MS 1, MS 3, MS 5 and MS 6. For apical bud, the callogenesis was observed on MS 1, MS 2 MS 7 and MS 9. The frequency of callogenesis was more on medium containing 2,4-D in higher concentration and low kinetin and also in medium with higher concentration of kinetin and low 2,4-D. This can be due to the fact that perhaps comparable concentration of each hormone is inhibiting each other effect. The node and apical bud cultures showed best response for callus induction perhaps due to the presence of meristematic tissues and auxins.

The observations are quite contradictory to the earlier works in which results were obtained on medium with higher concentration of auxin but not in cytokinins (Kantharajah et al., 1992 and Das et al., 1999). The results of this experiment also suggest that the hormones do not play a very significant effect on the responses. However, Wang et al., 2016 found that hormones play a very significant role in the induction of embryogenic callus from anther explants. They observed that a certain auxin-cytokinin ratios in medium is necessary for callus induction from anther culture of litchi and 2,4-D was the effective hormone in embryogenic callus induction. The 
embryogenic callus and haploid cultures were also obtained by $\mathrm{Fu}$ and Tang (1983), Fu (1990), Zhou et al., (1996), Yu and Chen (1998), Yu et al., (2000) and Das et al., (2016).

The present study was carried out to develop an efficient micropropagation protocol for litchi. Based on the findings of the experiments, it was found that all medium equally responded for the establishment of cultures. The level of contamination was highest in MS-7 mainly due to mycological associations. Among the explants, leaves showed maximum tendency of establishment followed by apical bud and nodes. Internodes exhibited browning. The medium MS-1 was best for swelling followed by MS-2 and MS3. MS-7, MS-9 showed equal effect on swelling. The medium MS-4, MS-5 and MS-6 was not very responsive for swelling.

The leaves and apical bud showed maximum swelling followed by nodes. No swelling was observed in internodes even after 20 days of inoculation. The medium with higher concentration of kinetin were best for callogenesis. Medium MS-1, MS-2 and MS-3 showed very good callus formation. The callus formation was also seen on MS-5, MS6 and MS-9. No callus was obtained on MS-4 and MS-7. The nodes showed best response for callus formation followed by apical bud and leaves. The callus formed in leaves is greenish while that of nodes and apical bud are creamish. The apical bud was found to be the most suitable explant for all responses.

\section{Acknowledgement}

The authors wish to express their acknowledgement to Dr. Rajendra Prasad Central Agricultural University, Pusa, Samastipur, Bihar for providing the technical, human and financial support for conducting this work.

\section{Author contributions}

All author have equally contributed to this article and its publication is approved by all authors.

\section{References}

Das, D.K., Rahman, A., Kumari, D. and Kumari, N. 2016. Synthetic seed preparation, germination and plantlet regeneration of litchi (Litchi chinensis Sonn.). American Journal of Plant Sciences, 7: 1395-1406. http://dx.doi. org/10.4236/ajps.2016.710133

Das, D.K., Shiv Prakash N. and Bhalla-Sarin, N. 1999. Multiple shoot induction and plant regeneration in litchi (Litchi chinensis Sonn.). Plant Cell Reports, 18: 691-695.

Emanuele, S., Lauricella, I. D. M., Calvaruso, G., D'Anneo, A., and Giuliano, M. 2017. Litchi chinensis as a functional food and a source of antitumor compounds: an overview and a description of biochemical pathways. Nutrients, 9: 1-15; doi:10.3390/ nu9090992.

Fu, L. 1990. Litchi: anther culture. In: Z. Chen et al., (Eds.), Handbook of Plant Cell Culture, Vol. 6. Perennial Crops. McGraw-Hill, New York, pp. 376-384.

Fu, L. and Tang, D. 1983. Introduction pollen plants of Litchi tree (Litchi chinensis Sonn.). Acta Genetica Sinica, 10: 369 374.

Goto, Y.B. 1960. Lychee and its processing. Pacific Region Food Conf., 1: 15-23.

Kantharajah, A.S., Dodd, W.A. and McConchie, C.A. 1989. The Possible Contribution of Tissue Culture to the Lychee Industry. Proceedings of the Second National Lychee Seminar, Cairns, Pp. 59-65.

Kantharajah, A.S., Dodd, W.A., and McConchie, A. 1992. In vitro embryo 
culture and induction of multiple shoots in lychee (Litchi chinensis Sonn.). Ann. Bot., 70: 153-156.

Lourith, N., Kanlayavattanakul, M., Chaikul, P., Chansriniyom, C. and Bunwatcharaphansakun, P. (2017). In vitro and cellular activities of the selected fruits residues for skin aging treatment. Anais da Academia Brasileira de Ciências, 89: 577-589. http://dx.doi.org/10.1590/0001-3765201 720160849.

Murashige, T. and Skoog, F. 1962. A revised medium for rapid growth and bioassays with tobacco tissue cultures. Physiol. Plant., 15: 473-497.

Naskar, S. and Mazumder, U.K. 2015. Antioxidant potential and hepatoprotectivity of hydromethanolic extract of Litchi chinensis Fruits: In vivo and in vitro studies. Iranian Journal of Pharmacology \& Therapeutics, 14: 1-9.

Taak, P. and Koul, B. 2016. Phytochemistry and pharmacological properties of Lychee (Litchi chinensis Sonn). Journal of Chemical and Pharmaceutical Research, 8: 35-48.
Wang, G., Li, H., Wang, S., Sun, J., Zhang, $\mathrm{X}$. and Wang, J. 2016. In vitro regeneration of 'Feizixiao' litchi (Litchi chinensis Sonn.). African Journal of Biotechnology, 15(22): 1026-1034.

$\mathrm{Yu}$, C. H. and Chen, Z. G. 1998. Embryogenic suspension culture and protoplast isolation in litchee. Chinese J.Tropical Crops 19: 16 - 20.

Yu, C. H., Chen. Z.G., Lu, L. X. and Lin, J. W. 2000. Somatic embyrogenesis and plant regeneration from litchi protoplasts isolated from embryogenic suspensions. Plant Cell, Tissue and Organ Culture, 61: 51 - 58.

$\mathrm{Yu}$, Y.B. 1991. Study on some factors in tissue culture of lychee (Litchi chinensis). Fujian Agric. Sci. Technol., 5: $17-18$.

Zhou, L. N., Kuang, Z. S., Ma, X. J., Chen, J. Q. and Cao, J. 1996. The study of factors affecting somatic embryogenesis in young embryo culture of Litchi chinensis. J. of Agric. Biotech. 4: 161 165.

\section{How to cite this article:}

Kumari Anjani and Harsh Kumar. 2018. In vitro Studies in Litchi chinensis - Effect of Explant and Medium. Int.J.Curr.Microbiol.App.Sci. 7(04): 2413-2422.

doi: https://doi.org/10.20546/ijcmas.2018.704.277 